\title{
Effects of Antioxidants on Asphalt Durability
}

\author{
Burton D. Beitchman*
}

(October 26, 1959)

\begin{abstract}
The mechanism by which asphalt degrades during weathering can be studied profitably by observing the action of materials which inhibit this degradation.

A number of antioxidants which are believed to function either by their ability to inhibit chain reactions or to decompose peroxides were studied for their effectiveness in retarding weight loss and promoting durability of roofing asphalts. Inhibitors of chain reactions in some cases inhibited weight loss without extending durability. Compounds which decompose peroxides were observed to be capable of extending the durability of an asphalt and also of retarding weight loss. Phenothiazine, which is believed to function primarily as a peroxide decomposer, proved to be the most outstanding of the inhibitors tested.

A study made in one asphalt of the dependence of phenothiazine activity on concentration indicated that a concentration of 2 percent was optimum. In several other asphalts, 2 percent phenothiazine retarded weight loss to varying extents without significantly altering the durability of the asphalt.

Synergistic activity was shown by the use of an inhibiting mixture containing phenothiazine and $N$-phenyl-2-naphthylamine.

The results of this study support the hypothesis of a free radical process being involved to a considerable degree in asphaltic degradation during weathering.
\end{abstract}

\section{Introduction}

Asphalt is the material that is used most widely for roofing in the United States; however, little information is available concerning the mechanism of degradation of roofing asphalt during exposure to the weather.

This paper reports a study of the effect of two classes of antioxidants on the durability and weight loss of asphalts used as roof coatings during accelerated weathering. These antioxidants have been shown to be effective in inhibiting air oxidation of hydrocarbons, a reaction which is considered to be a free radical chain process. The mechanism, first proposed by Criegee and coworkers $[1]^{1}$ and Bolland and Ten Have [2], and also described by Kennerly and Patterson [3] is:

Initiation $\left\{\begin{array}{l}\mathrm{ROOH} \rightarrow \mathrm{RO} \cdot+\mathrm{HO} . \\ \mathrm{RO} \cdot\left(\mathrm{HO} \cdot \mathrm{HO}_{2} \cdot\right)+\mathrm{RH} \\ \rightarrow \mathrm{ROH}\left(\mathrm{H}_{2} \mathrm{O}, \mathrm{H}_{2} \mathrm{O}_{2}\right)+\mathrm{R} . \\ \mathrm{AH}+\mathrm{O}_{2} \rightarrow \mathrm{A} \cdot+\mathrm{HO}_{2} .\end{array}\right.$

Propagation $\left\{\begin{array}{l}\mathrm{R} \cdot+\mathrm{O}_{2} \rightarrow \mathrm{RO}_{2} . \\ \mathrm{RO}_{2} \cdot+\mathrm{RH} \rightarrow \mathrm{ROOH}+\mathrm{R} .\end{array}\right.$

Termination $2 \mathrm{RO}_{2} \cdot \rightarrow \mathrm{X}$

Inhibition

$$
\left\{\begin{array}{l}
\mathrm{RO}_{2} \cdot\left(\mathrm{RO} \cdot, \mathrm{HO} \cdot \mathrm{HO}_{2} \cdot\right)+\mathrm{AH} \rightarrow \mathrm{ROOH} \\
\quad\left(\mathrm{ROH}, \mathrm{H}_{2} \mathrm{O}, \mathrm{H}_{2} \mathrm{O}_{2}\right)+\mathrm{A} \cdot \\
\mathrm{RO}_{2} \cdot\left(\mathrm{RO} \cdot, \mathrm{HO}, \mathrm{HO}_{2} \cdot\right)+\mathrm{A} \cdot \rightarrow \mathrm{Y}
\end{array}\right.
$$

The above equations have been explained by Kennerly and Patterson [3] essentially as follows. Peroxides, which are present or form in the hydrocarbons, initially cleave into free radicals when

\footnotetext{
* Present address, Houdry Process Corp., Linwood, Pa.

1 Figures in brackets indicate the literature references at the end of this paper.
}

supplied with energy in the form of heat or ultraviolet light (eq (1)). Alkyl radicals are formed by reaction of these radicals with hydrocarbon molecules (eq (2)). These reactions are termed initiation steps in the oxidation. A chain reaction then ensues in which more molecules of the hydrocarbon react (eqs (4) and (5)). The chain process can terminate with the dimerization of two peroxy radicals to form an inactive product (eq (6)).

One type of antioxidant functions by its ability to intercept radicals which would propagate the chain reaction (eqs (7) and (8)). Other mechanisms have been suggested by which these inhibitors may intercept the propagating radicals $[4,5]$. The inhibitor can contribute to initiation (eq (3)) and the rate of this reaction is directly dependent on inhibitor concentration.

The class of antioxidants, referred to as peroxidedecomposers, function by their ability to accelerate decomposition of peroxides into products which would be inactive in initiating or propagating a free radical oxidation. Inhibitors of chain reactions have been found to be superior for low temperaturelow concentration applications and have been used for protection of gasoline in storage [3]. Compounds which decompose peroxides have been found to be superior for high temperature-high concentration applications and have been used in automotive lubricating oils, where high temperatures are encountered [3].

Asphalts are a complex mixture, containing hydrocarbons for the most part, and on exposure to natural and accelerated weathering yield a variety of oxidation products. Ultraviolet light produces deteriorating effects during these exposures, and thus it appears reasonable to propose that a free radical process may be one of the principal means by which asphalt degrades. A study of the action 
of inhibitors of chain reactions and peroxide-decomposers on durability and weight loss of asphalts during accelerated weathering may indicate whether a free radical process is involved in this degradation.

\section{Procedure}

Each of the asphalts was melted in a seamless ointment can on a hot plate and stirred periodically until the asphalt was fluid. The inhibitors, which are listed in tables 1 to 5 , were added to the asphalt and stirred for several minutes. Exposure specimens were prepared by the hydraulic press method [6]. The asphalts used in this study were selected on the basis of previously determined values ${ }^{2}$ for durability in order to include asphalts with a wide range of durability. These asphalts are identified by the symbols $A$ to $F$. Four panels of each specimen were prepared except for samples of asphalt $A$ and in this case only three panels for each specimen were prepared. The panels of asphalt were exposed in accelerated weathering machines to $51 \mathrm{~min}$ of light and $9 \mathrm{~min}$ of cold $\left(40^{\circ} \mathrm{F}\right)$ water spray and light during every bour of exposure. Panels were weighed periodically to determine weight loss. The method for determining durabilities was that described by Greenfeld [6]. This procedure involves periodic inspection of panels with a high voltage electric probe. The failures in the coating are determined by making a spark photograph of the surface. A 60-square grid is placed over the photograph and when half of the squares show the presence of cracks or holes, the coating is considered to have failed. Durability is defined as the time required to reach this condition. Softening points ${ }^{3}$ of uninhibited asphalts in this report ranged from $208^{\circ}$ to $224^{\circ} \mathrm{F}$ and the penetrations ${ }^{4}$ at $77^{\circ} \mathrm{F}$ from 16 to 20.5 .

\section{Results}

A number of compounds which are considered to function as antioxidants by peroxide decomposition or inhibition of chain reactions were tested for their activity in retarding degradation effects in asphalt caused by weathering. The inhibitors of chain reactions used in this study were classified as such on the basis of studies by other investigators $[4,7]$. Compounds identified as peroxide decomposers were part of a group discussed by Kennerly and Patterson [3]. The effectiveness of the inhibitors of chain reactions in retarding weight loss and promoting durability is shown in table 1 . The durability is measured in terms of average number of hours to failure (col. 4). An arbitrarv point has been chosen for comparison of weight losses in the exposed asphalts. The point chosen, $594 \mathrm{hr}$, is close to the failure points of the least durable asphalts.

Some of the values of percent weight loss at $594 \mathrm{hr}$ were determined by interpolation or extrapolation when weighings were not made at this exact interval. Resorcinol and hydroquinone were observed to

\footnotetext{
2 Unpublished data of S. H. Greenfeld and coworkers.

3 ASTM Method D36-26.

4 A STM Method B5-52.
}

TABLE 1. Antioxidant activity of inhibitors of chain reactions

\begin{tabular}{|c|c|c|c|c|}
\hline Asphalt & Inhibitor & $\begin{array}{c}\text { Softening } \\
\text { point }\end{array}$ & $\begin{array}{c}\text { Dura- } \\
\text { bility } \\
\text { (avg } \mathrm{hr} \\
\text { to failure) }\end{array}$ & $\begin{array}{l}\text { Avg wt } \\
\text { change } \\
\text { at } 594 \mathrm{hr}\end{array}$ \\
\hline $\begin{array}{l}A \\
A \\
A \\
A \\
A\end{array}$ & $\begin{array}{l}\text { None } \\
1 \% \text { resorcinol } \\
1 \% \text { hydroquinone and } 1 \% \text { resorcinol } \\
1 \% \text { hydroquinone } \\
1 \% \text { diphenylamine }\end{array}$ & $\begin{array}{l}\circ F \\
219 \\
218 \\
214 \\
218 \\
214\end{array}$ & $\begin{array}{l}682 \\
725 \\
705 \\
682 \\
705\end{array}$ & $\begin{aligned} & \% \\
&-10.46 \\
&-9.76 \\
&-9.75 \\
&-9.39 \\
&-8.99\end{aligned}$ \\
\hline $\begin{array}{l}B \\
B \\
B \\
B\end{array}$ & $\begin{array}{l}\text { None } \\
1 \% \text { resorcinol- } \\
1 \% \text { t-butyl phenol } \\
1 \% \text { hydroquinone }\end{array}$ & $\begin{array}{l}221 \\
219 \\
225 \\
213\end{array}$ & $\begin{array}{l}639 \\
572 \\
616 \\
660\end{array}$ & $\begin{array}{l}-8.45 \\
-9.91 \\
-8.92 \\
-8.91\end{array}$ \\
\hline $\begin{array}{l}B \\
B \\
B \\
B \\
B\end{array}$ & $\begin{array}{l}1 \% \text { diphenylamine } \\
1 \% \mathrm{~N}, \mathrm{~N} \text {-diethyl-p-phenylenediamine } \\
1 \% \alpha \text {-naphthylamine } \\
1 \% \mathrm{~N} \text {-phenyl-2-naphthylamine } \\
5 \% \text { diphenylamine }\end{array}$ & $\begin{array}{l}226 \\
218 \\
223 \\
216 \\
191\end{array}$ & $\begin{array}{l}660 \\
616 \\
639 \\
749 \\
901\end{array}$ & $\begin{array}{l}-8.26 \\
-7.83 \\
-7.57 \\
-6.13 \\
-5.67\end{array}$ \\
\hline
\end{tabular}

reduce weight loss to a slight extent in asphalt $A$ and on the other hand to promote weight loss in asphalt $B . \quad N$-phenyl-2-naphthylamine, $\alpha$-naphthylamine, and $N, N$-diethyl-p-phenylenediamine were found to be the best of the antioxidants tested which function by free radical inhibition. The use of 5 percent diphenylamine in comparison to 1 percent of this inhibitor resulted in greater weight loss in the early stages of exposure but in significantly less weight loss in later stages. A slight increase in durability as measured by the crack pattern also resulted when 5 percent diphenylamine was used. These desirable effects, however, were attended by a marked decrease in softening point. The changes in softening point produced by the inhibitors can be obtained from table 1 . Curves of weight change as a function of exposure time for asphalts to which have been added compounds which inhibit chain reactions are shown in figures 1,2 , and 3 .

The effectiveness of several antioxidants which function as peroxide decomposers is shown in table 2 . In order to compare the relative effectiveness of these inhibitors, the same number of moles were used in each case. Phenothiazine was found to

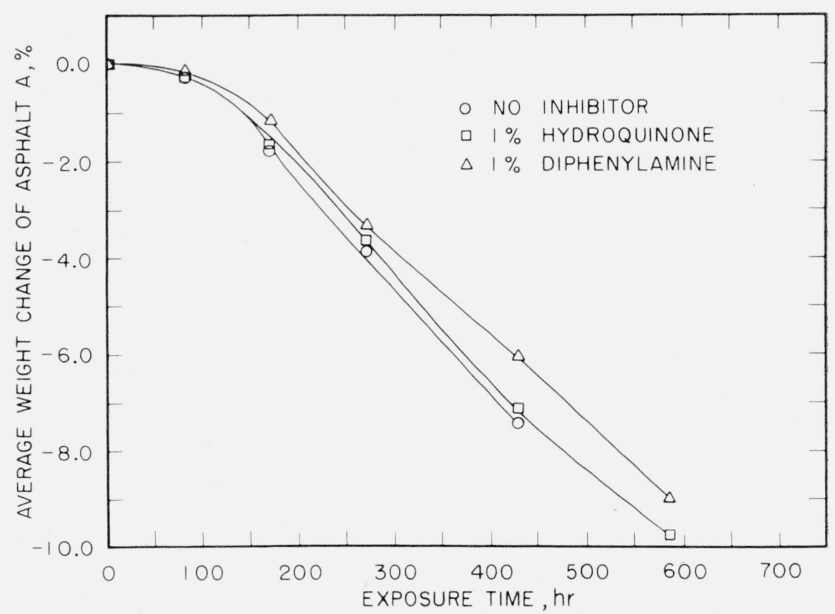

Figure 1. The effect of inhibitors of chain reactions on weight loss of asphalt $A$. 


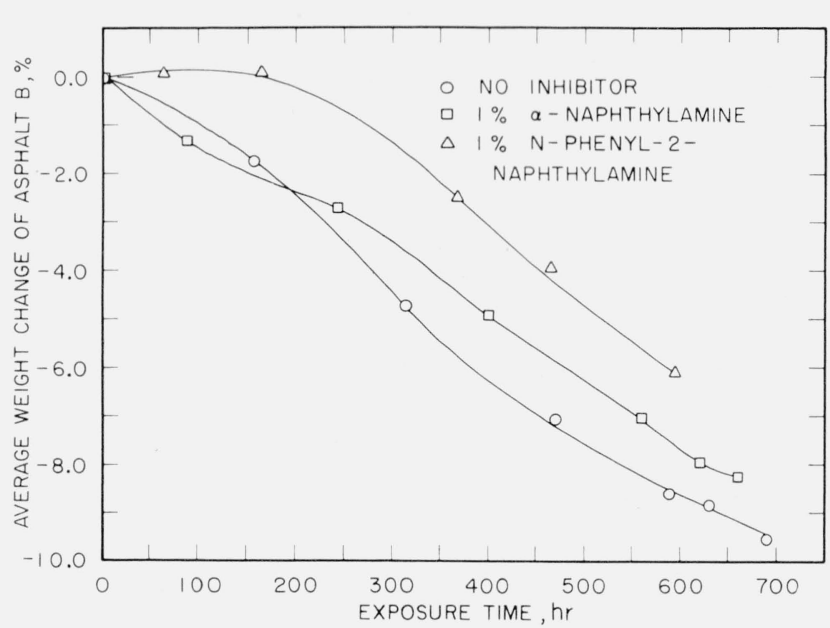

FiguRE 2. The effect of inhibitors of chain reactions on weight loss of asphalt $B$.

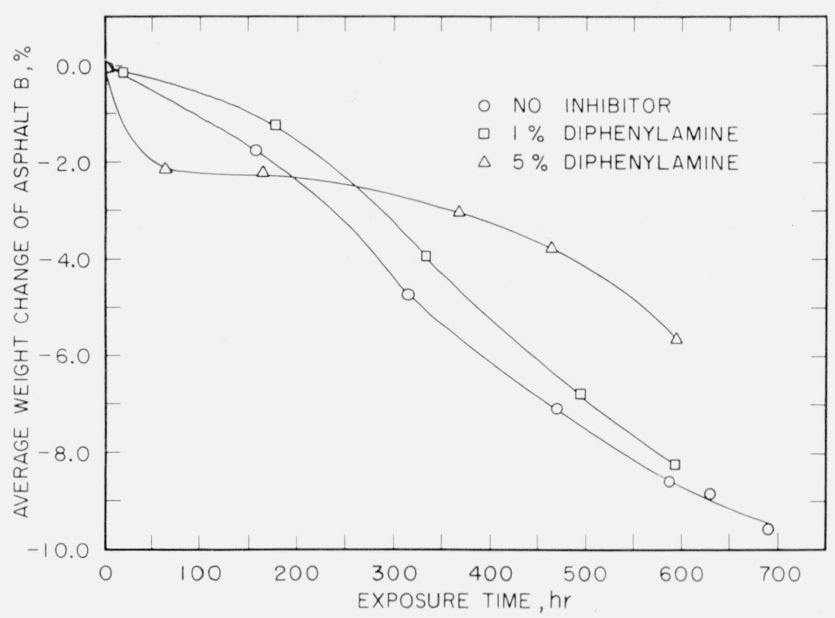

Figure 3. The effects of two concentrations of diphenylamine on the weight loss of asphalt $B$.

excel in its ability to retard weight loss and promote durability in asphalt $B$. The use of phenothiazine in asphalt to provide nondusting asphaltic coatings has been patented [8]. Other peroxide decomposers proved capable of extending the durability of the asphalt and retarding weight loss caused by accelerated weathering. Curves demonstrating the effect of two peroxide decomposers on weight loss as a function of time are shown in figure 4.

TABLE 2. Antioxidant activity of compounds uhich decompose peroxides

\begin{tabular}{|c|c|c|c|c|}
\hline Asphalt & Inhibitor & $\begin{array}{c}\text { Softening } \\
\text { point }\end{array}$ & $\begin{array}{l}\text { Durability } \\
\text { (avg hr to } \\
\text { failure) }\end{array}$ & $\begin{array}{c}\text { Avg wt } \\
\text { change at } \\
594 \mathrm{hr}\end{array}$ \\
\hline $\begin{array}{l}B \\
R \\
R \\
R \\
R \\
B\end{array}$ & $\begin{array}{l}2.0 \% \text { phenothiazine } \\
1.79 \% \text { butyl sulfone } \\
1.47 \% \text { butyl sulfide } \\
1.87 \% \text { phenyl sulfide } \\
\text { None. }\end{array}$ & $\begin{array}{l}{ }^{\circ} F \\
212 \\
218 \\
226 \\
218 \\
221\end{array}$ & $\begin{array}{r}3,180 \\
945 \\
1,142 \\
1,120 \\
638\end{array}$ & $\begin{array}{l}\% \\
+0.33 \\
-7.30 \\
-7.35 \\
-8.16 \\
-8.45\end{array}$ \\
\hline
\end{tabular}

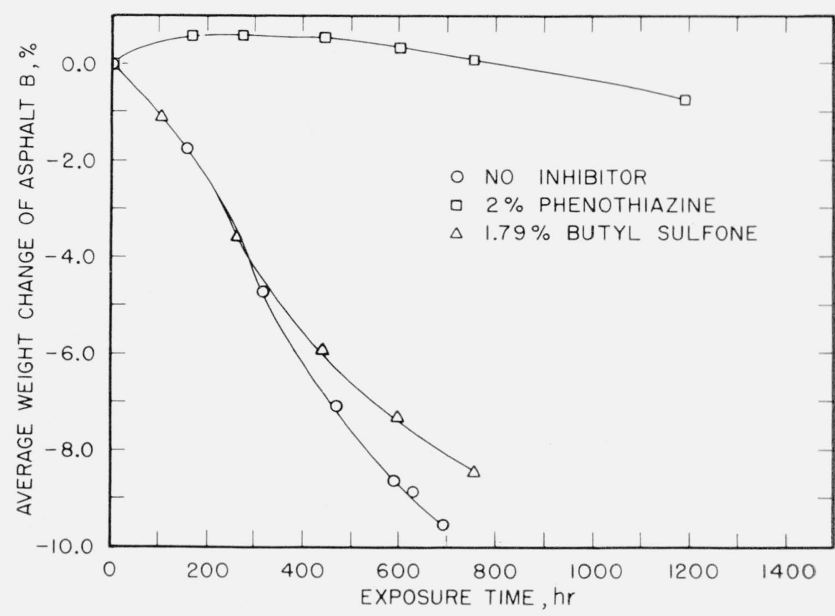

FIGURE 4. The effect of compouna's which decompose peroxides on weight loss of asphalt $B$.

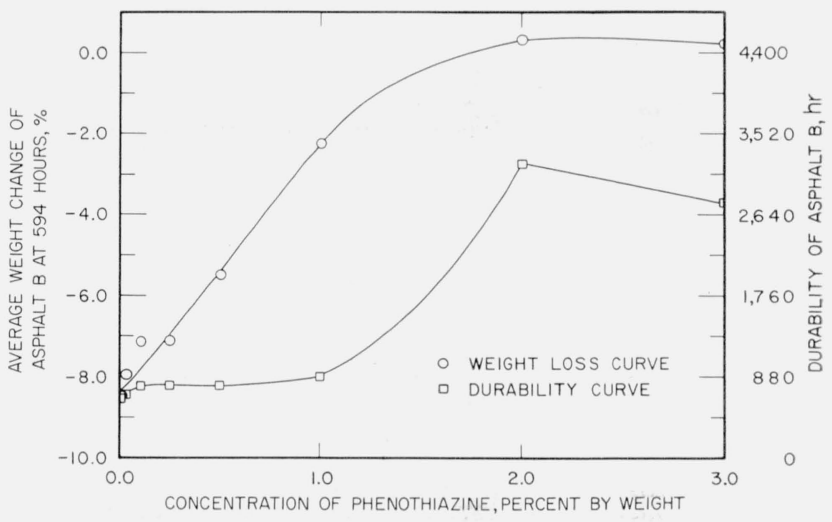

FIGURE 5. The concentration dependence of phenothia zine activity in asphalt $B$.

A study was made of the dependence of phenothiazine activity on concentration of inhibitor used. The activity of the inhibitor in inhibiting weight loss showed an approximately linear dependence up to 1 percent and then reached maximum activity at 2 percent (fig. 5 and table 3). The effect of inhibitor concentration on durability was slight up to 1 percent, but an abrupt increase in durability was observed when a concentration of 2 percent inhibitor was used (fig. 5). The use of 1 percent or more inhibitor produced a decrease in softening point. A concentration of 10 percent inhibitor produced a poor coating material with a low softening point although weight loss inhibition was still quite excellent.

Four other asphalts of varying durabilities were studied to determine the ability of phenothiazine to improve their weathering characteristics (table 4). 
TABLE 3. Concentration dependence of phenothiazine as an antioxidant in asphalt $B$

\begin{tabular}{c|c|c|c}
\hline \hline $\begin{array}{c}\text { Concentra- } \\
\text { tion of } \\
\text { phenn- } \\
\text { thiazine }\end{array}$ & $\begin{array}{c}\text { Softening } \\
\text { point of } \\
\text { inhibited } \\
\text { asphalt }\end{array}$ & $\begin{array}{c}\text { Durability } \\
\text { (avg hr to } \\
\text { failure) }\end{array}$ & $\begin{array}{c}\text { Avg wt } \\
\text { change at } \\
594 \text { hr }\end{array}$ \\
$\%$ & ${ }^{\circ} F$ & & $\%$ \\
0.000 & 221 & 639 & -8.45 \\
.002 & 227 & 616 & -7.88 \\
.015 & 225 & 682 & -7.96 \\
.100 & 226 & 770 & -7.12 \\
.250 & 223 & 692 & -7.10 \\
.500 & 221 & 692 & -5.45 \\
1.000 & 218 & 880 & -2.23 \\
2.000 & 212 & 3,180 & +0.323 \\
3.000 & 210 & 2,780 & +0.221 \\
10.000 & 181 & 528 & +0.49 a \\
& & & \\
\hline
\end{tabular}

a Value of weight loss at $528 \mathrm{hr}$.

TABLE 4. Antioxidant activity of phenothiazine in other asphalts

\begin{tabular}{c|c|c|c}
\hline \hline \multirow{2}{*}{ Asphalt } & $\begin{array}{c}\text { Concentra- } \\
\text { tion of } \\
\text { pheno- } \\
\text { thiazine }\end{array}$ & $\begin{array}{c}\text { Durability } \\
\text { (avg hr to } \\
\text { failure) }\end{array}$ & $\begin{array}{c}\text { Avg wt } \\
\text { change at } \\
594 \mathrm{hr}\end{array}$ \\
$C$ & $\%$ & & $\%$ \\
$C$ & 0.0 & 1,210 & -3.31 \\
$C$ & 1.0 & 1,361 & -3.28 \\
$D$ & 2.0 & 1,340 & -0.90 \\
$D$ & 0.0 & 1,608 & -6.32 \\
$E$ & 1.0 & 1,718 & -4.02 \\
$E$ & 0.0 & 815 & -6.43 \\
$E$ & 1.0 & 859 & -4.29 \\
$F$ & 2.0 & 880 & -0.83 \\
$F$ & 0.0 & 1,450 & -4.69 \\
& 1.0 & 1,540 & -3.45 \\
\hline
\end{tabular}

The durabilities of these four asphalts were increased only slightly by the use of phenothiazine in concentrations of 1 or 2 percent. Weight-loss inhibition, however, was quite significant when a concentration of 2 percent phenothiazine was used (figs. 6 and 7 ). A concentration of 1 percent phenothiazine produced some weight loss inhibition in asphalts $D, E$, and $F$, but no significant effect in asphalt $C$.

In table 5 the synergistic action of a combination of peroxide decomposer and an inhibitor of chain reactions is shown. The combination of phenothiazine and $N$-phenyl-2-naphthylamine produces a greater increase in durability than would be obtained if the effects of each inhibitor in combination were merely additive. The combination also reduces weight loss to a greater extent than the individual inhibitors during later hours of exposure (fig. 8).

Small percentages of asphaltic fractions from a good weathering asphalt, $C$, were added to a less durable asphalt, $B$, to determine whether good weathering characteristics might be imparted to the latter. The fractions used were the asphaltenes and maltenes which are the pentane-insoluble and pentane-soluble fractions of asphalt, respectively. No significant improvements were observed in weight loss inhibition or durability.

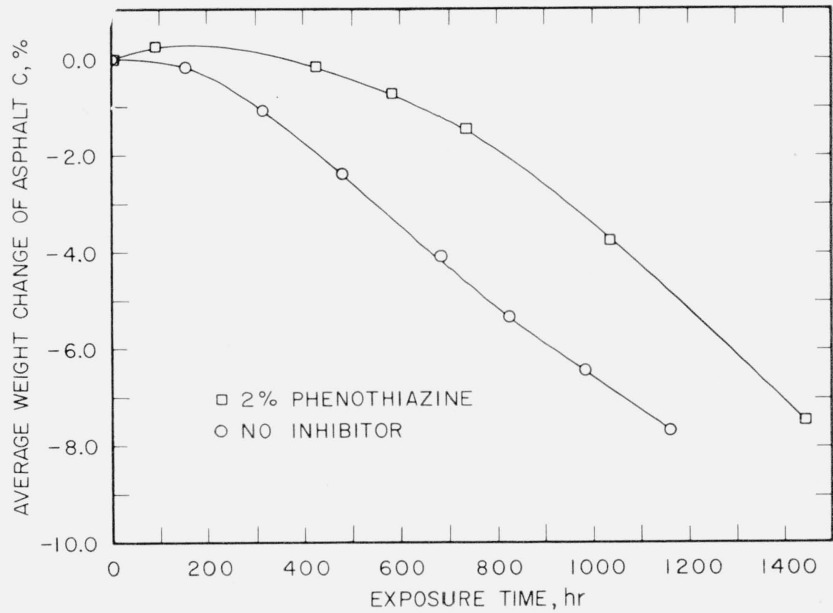

Figure 6. The effect of phenothiazine (2 percent by weight) on weight loss of asphalt $C$.

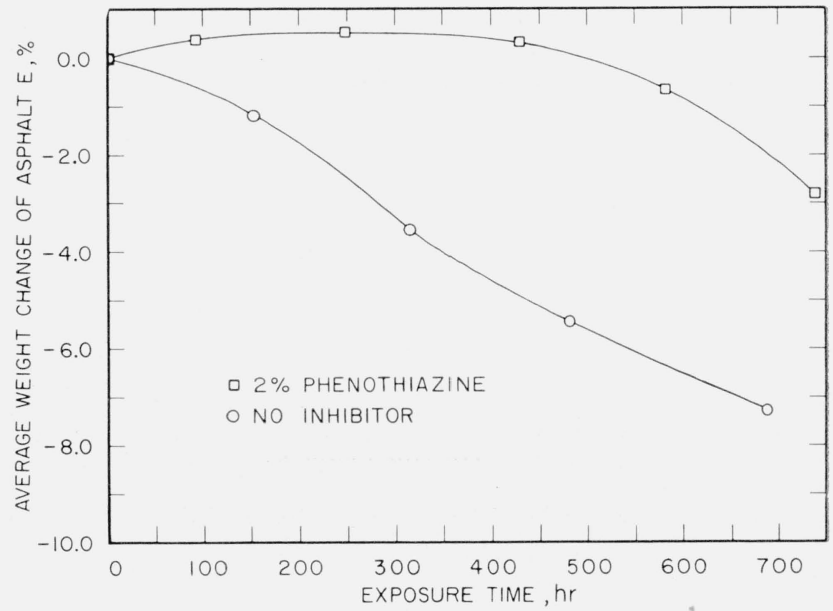

FIGURE 7. The effect of phenothia zine (2 percent by weight) cn weight less of asphalt $E$.

TABLE 5. Additional antioxidant studies

\begin{tabular}{|c|c|c|c|c|}
\hline Asphalt & Inhibitor & $\begin{array}{l}\text { Softening } \\
\text { point }\end{array}$ & $\begin{array}{l}\text { Durahility } \\
\text { (avg hr to } \\
\text { failure) }\end{array}$ & $\begin{array}{c}\text { Avg wt } \\
\text { change at } \\
594 \mathrm{hr}\end{array}$ \\
\hline $\begin{array}{l}R \\
R \\
R \\
B\end{array}$ & $\begin{array}{l}\text { None- } \\
1 \% \text { phenothiazine } \\
1 \% \mathrm{~N} \text {-phenyl-2-naphthylamine } \\
1 \% \text { phenothiazine plus } 1 \% \\
N \text {-phenyl-2-naphthylamine } \\
1.34 \% \mathrm{C} \text { maltenes. } \\
3.00 \% \mathrm{C} \text { maltenes } \\
1.34 \% \mathrm{C} \text { asphaltenes } \\
3.00 \% \mathrm{C} \text { asphaltenes }\end{array}$ & $\begin{array}{l}\circ F \\
221 \\
218 \\
216 \\
\\
212 \\
\\
225 \\
221 \\
229 \\
222\end{array}$ & $\begin{array}{r}638 \\
880 \\
748 \\
1,300 \\
\\
705 \\
660 \\
638 \\
550\end{array}$ & $\begin{array}{c}\% \\
-8.45 \\
-2.23 \\
-6.13 \\
-1.89 \\
-7.59 \\
-7.40 \\
-7.86 \\
-7.80\end{array}$ \\
\hline
\end{tabular}




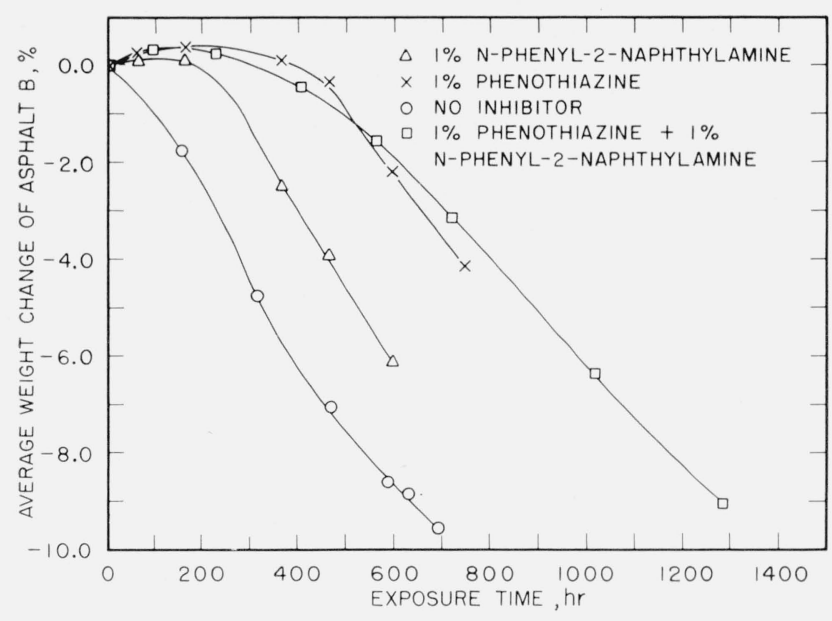

FIGURE 8. The effect of a combination of an inhibitor of chain reactions and a peroxide decomposer on weight loss of asphalt $B$.

\section{Discussion of Results and Conclusions}

The results of this study strongly support the hypothesis that asphaltic degradation during accelerated weathering involves a free radical oxidation. The similarity in effects produced by natural and accelerated weathering suggests that this process also occurs in natural weathering. Antioxidants which function by peroxide decomposition have been shown capable of extending the durability of asphalts and inhibiting weight loss to varying extents. The antioxidant properties of peroxide decomposers show a marked concentration dependence in mineral oils [1]. This dependence was established in asphalt also in a study made of the dependence of phenothiazine activity on concentration. Phenothiazine, a peroxide decomposer, in concentrations of 2 percent by weight, produced excellent inhibition of weight loss in the several asphalts tested.

Phenothiazine, in concentrations of 2 percent, also extended the durability of one asphalt more than fivefold, but had no great effect on the durabilities of two other asphalts. Inhibitors of chain reactions were shown to be capable of retarding weight loss to varying extents but did not produce significant increases in durability in the asphalts tested. The individual characteristics of the asphalts determine the effectiveness of a particular inhibitor. A similar dependence of additive effectiveness was also observed by Greenfeld [9] in studies of the eifects of mineral additives on the durability of coating-grade roofing asphalts.
The reactions producing weight losses in asphalts involve formation of gaseous decomposition products [10] and water-soluble products [11]. If the uninhibited asphalts are examined for weight loss in the early stages of exposure, a slight gain in weight during an induction period may be observed rather than a loss in weight (asphalt $C$ in fig. 6). This induction period which is commonly observed in free radical processes can be extended by the use of phenothiazine, considered to be a peroxide decomposer (figs. 6, 7, and 8) and also by the use of 1 percent $N$-phenyl-2-naphthylamine, an inhibitor of chain reactions.

A synergistic effect has been observed when a combination of a peroxide decomposer and an inhibitor of chain reactions was used. This produced a greater increase in durability than would result if the effects of each inhibitor were merely additive. Synergistic effects have also been observed when inhibitors of chain reactions and peroxide decomposers are used in combination for protection of mineral oil [3].

Addition of small percentages of asphaltenes and maltenes of a more durable asphalt to a less durable asphalt produced no increase in durability or inhibition of weight loss. These tests were conducted to determine whether natural antioxidants exist in more durable asphalts. On the basis of these tests alone, one cannot conclude that natural antioxidants are either present or absent since such inhibitors may be present in low concentrations in the original asphalt.

\section{References}

[1] R. Criegee, H. Pilz, and H. Flygare, Ber. 72, 1799 (1939). [2] J. L. Bolland and P. Ten Have, Trans. Faraday Soc. 43, 201 (1947).

[3] G. W. Kennerly and W. L. Patterson, Jr., Ind. Eng. Chem. 48, 1917 (1956).

[4] C. J. Pedersen, Ind. Eng. Chem. 48, 1881 (1956).

[5] G. S. Hammond, C. E. Boozer, C. E. Hamilton, and J. N. Sen, J. Am. Chem. Soc. $7 \boldsymbol{g}, 3238$ (1955).

[6] S. H. Greenfeld, ASTM Bull. 193, 50 (1953).

[7] G. S. Hammond, C. E. Boozer, C. E. Hamilton, and J. N. Sen, J. Am. Chem. Soc. 78, 3240 (1955).

[8] E. W. Mertens (to California Research Corp.), U.S. Pat. 2,797,169 (June 25, 1957).

[9] S. H. Greenfeld, NBS Building Materials and Structures Report 147 (1956).

[10] R. R. Thurston and E. C. Knowles, Ind. Eng. Chem. 33, 320 (1941).

[11] O. G. Strieter and H. R. Snoke, A modified accelerated weathering test for asphalts and other materials, J. Research NBS 16, 481 (1936) RP886.

Washington, D.C.

(Paper 64C1-19) 